Case Study

\title{
Effect of Hijamah (Dry Cupping) on Frozen Shoulder: A Case Study
}

\author{
Mohammad Abid', Humera Shazia ${ }^{2}$, Sadaf Khan ${ }^{3}$, Tamanna Nazli4, Raja Ram Mahto
}

${ }^{1}$ Research Associate, Hijamah Section, All India Institute of Ayurveda, New Delhi, India.

${ }^{2}$ Senior Research Fellow (Unani), Hijamah Section, All India Institute of Ayurveda, New Delhi, India.

${ }^{3}$ Research Scholar, Department of Samhita Siddhant, All India Institute of Ayurveda, New Delhi, India.

${ }^{4}$ Research Officer, Unani Medical Centre, Safdarjung Hospital, New Delhi, India.

${ }^{5}$ Assistant Professor, Department of Kaya Chikitsa (Internal Medicine), All India Institute of Ayurveda, New Delhi, India.

DOI: https://doi.org/10.24321/2394.6547.202105

\section{I $\quad \mathbf{N} \quad \mathbf{F} \quad \mathbf{O}$}

\section{Corresponding Author:}

Mohammad Abid, Hijamah section, All India Institute of Ayurveda, New Delhi, India.

E-mail Id:

mabid884@gmail.com

Orcid Id:

https://orcid.org/0000-0002-1261-3117

How to cite this article:

Abid M, Humera S, Khan S, Nazli T, Mahto RR.

Effect of Hijamah (Dry Cupping) on Frozen Shoulder: A Case Study. J Adv Res Ayur Yoga Unani Sidd Homeo. 2021;8(1\&2):14-17.

Date of Submission: 2021-05-09

Date of Acceptance: 2021-06-22

\section{$\begin{array}{lllllllllllll}\mathbf{A} & \mathbf{B} & \mathbf{S} & \mathbf{T} & \mathbf{R} & \mathbf{A} & \mathbf{C} & \mathbf{T}\end{array}$}

Frozen shoulder or adhesive capsulitis is one of the most common causes of shoulder pain and disability in the general population. Its prevalence is $2-5 \%$ in the general population and $10-20 \%$ among diabetics. It predominantly affects females and most commonly affects people between the ages of 40 and 60 years. The left shoulder is more likely to be affected, with both shoulders affected in $12 \%$ of cases. A case study is presented to illustrate the clinical presentation, aetiology, diagnosis, radiological assessment, and management of frozen shoulder through Hijamah bila shurt (dry cupping) in a 60-year-old diabetic male patient. The present case was studied for over 8 weeks; Hijamah (dry cupping) was done on prescribed points for the affected shoulder twice a week for 8 weeks, and assessment was done at baseline and every 2 weeks. This study concluded that regimental therapy Hijamah bila shurt (dry cupping) has a significant effect in reducing pain, stiffness of joints, and increasing range of motion in frozen shoulder.

Keywords: Frozen Shoulder, Case Report, Hijamah, Cupping, Adhesive Capsulitis, VAS, ROM

\section{Introduction}

Frozen shoulder or adhesive capsulitis is periarthritis involving the periarticular soft tissues of the shoulder, one of the most common causes of shoulder pain and disability in the general population. ${ }^{1,2}$ Prevalence is $2-5 \%$ in general population and $10-20 \%$ among diabetics. ${ }^{2}$ It predominantly affects females and people between the ages of 40 and 60 years. The left shoulder is more likely to be affected. ${ }^{2,3}$ Both shoulders have been found to be affected in $12 \%$ of individuals. Recurrence is rare in the same shoulder. ${ }^{4}$ The aetiology of adhesive capsulitis remains unknown. However, rotator cuff disease, impingement syndrome, chest or breast surgery, diabetes, prolonged immobilisation, age, thyroid disease, various medical problems (pulmonary disease, myocardial infarction, cerebrovascular accident), and autoimmune disease are associated with the development of adhesive capsulitis. ${ }^{5}$

Adhesive capsulitis usually manifests itself in 12-42 months, but it may be as early as 6 months or as late as 10 years. ${ }^{2}$ Lundberg classified frozen shoulder syndrome into "primary" and "secondary". ${ }^{6}$ Primary adhesive capsulitis pertains to those patients who present with no significant findings in history, clinical examination, or radiographic evaluation to explain their motion loss and pain. However, patients with 
secondary adhesive capsulitis disclose a trauma or surgery to the affected upper extremity prior to their shoulder symptomatology. ${ }^{7}$ Reeves identified three phases in the natural history of the frozen shoulder syndrome: (1) an early painful phase lasting 10-36 weeks; (2) an intermediate, stiff, or frozen phase characterised mainly by a limited range of motion lasting 4-12 months; (3) a recovery or thawing phase lasting 5-24 months or more. ${ }^{8}$

\section{Radiographic Examination}

A study by Pearsall and Speer recommend anteroposterior (AP), axillary and supraspinatus outlet views of the affected shoulder. ${ }^{9}$ Plain x-rays of shoulders range from normal to osteopenic with degenerative changes, calcium deposits, or cystic changes in long-standing cases. ${ }^{3}$ The AP film is assessed for osteopenia, bony abnormalities, and superior migration of the head of the humerus. The axillary view is obtained to assess glenohumeral subluxation or glenoid or humeral head articular damage. Shoulder arthrography shows loss of the normal axillary recess and a significantly decreased capsular volume. ${ }^{5}$

\section{A Brief on Hijamah}

\section{Hijamah as per Unani Concept}

Cupping therapy (Hijamah) is one of the regimental therapies effective in the alleviation of pain and tenderness. It is a proven way to treat fibromyalgia, arthritis, joint pain, and carpal tunnel symptoms without using invasive measures. The main objectives of Hijamah as per the Unani system of medicine are evacuation of matter (Ikhraj-emawad/ Tanqiya Ghalba-e-khilt) when the cause of pain may be accumulation of morbid matter; diversion of matter (Imala-e-mawad, Aleeluzwa se uzwa-e-shirkikijanib) to the associated organ; Taskeen alam (to alleviate pain) Tehleele auram (to resolve inflammation), and Tehleele riyah and Taskheene muqam (local calorific). ${ }^{10}$

\section{Probable Mode of Action of Hijamah as per Modern Concept}

Local Effect of Hijamah: Humans are provided with two types of immunity: innate and acquired. Hijamah is a planned, sterile injury, induced under controlled conditions which causes physical disruption of keratinocyte present under epidermis. The innate immunity senses a high-risk situation and releases antimicrobial peptides (AMPs) to eliminate invading microbes. Hijamah is sensed by innate immunity as a "high-risk situation" following local injury. It causes the innate immunity to release three AMPs like human $\beta$-defensin-3, neutrophil gelatinase-associated lipocalin, and secretory leukocyte protease inhibitor through activation of the epidermal growth factor receptor. One day after Hijamah, neutrophil influx occurs, this causes clearance of microbes from the site of Hijamah. On the third and fourth day of Hijamah, neutrophils also cause trans- activation of AMPs. These three AMPs increase resistance to overt infection and microbial colonisation.

\section{Inflammatory Effects of Hijamah}

Hijamah (surgical incision) evokes an early or immediate, prolonged, localised inflammatory response, and the following events occur at the Hijamah site: as a result of primary sucking at the cupped area, blood flow is increased and the area appears red in colour. Increased permeability of blood vessels results in an exudation of plasma proteins and fluid into the tissue, which causes swelling or oedema. ${ }^{9}$ The vacuum also attracts a fresh circulation of lymph. This fluid reduces inflammation and facilitates recruitment of immune cells that support the healing process.

\section{Material and Methods}

This study was carried out at Hijama section at All India Institute of Ayurveda, New Delhi in 2019. Patient consent had been taken to publish the results of the study without revealing personal identity. Hijamah kit including mediumsized cups and a vacuum pump was used to apply the cups over the affected area. A goniometer was used to measure the range of motions at the affected shoulder joint.

\section{Case History}

A 60-year-old diabetic male patient presented with left shoulder pain. Pain had started one year before and stiffness had developed gradually. During that time, he took treatment from his family physician who prescribed him analgesics and anti-inflammatory medications, and referred him to physiotherapy. The physiotherapy treatment included mobilisation of the left shoulder and neck, and exercises (using small weights, rubber tube and pulleys), for three months. He also received massages for five months. In spite of continued treatment, his pain and inability to move his left shoulder got worse. At this time the patient presented to the Hijamah clinic at All India Institute of Ayurveda, New Delhi with pain and very limited movement in the left shoulder and with a sharp pain in the posterior left arm. He complained of difficulty in moving his left arm and having a hard time dressing and combing hair with his left hand. The pain was aggravated by any movement of the left arm, and lying on the left arm. He was awakened at night when he rolled onto the affected arm.

The history indicated a gradual onset of pain and stiffness. The pain was quite intense and was often referred to as insertion of the deltoid, the deltoid muscle region, and the bicipital tendon. The pain was aggravated by the shoulder movements, especially external rotation, and sleeping on the involved side, and was relieved by limiting use of the extremity. There was often soreness in the proximal upper back and neck which may be as a result of compensatory overuse of the accessory musculature (trapezius, scalene, levator scapulae, rhomboid muscles). 
The patient complained of difficulty while putting on a coat, reaching into the hip pocket for a wallet, and combing his hair. These symptoms closely resemble that of a frozen shoulder.

\section{Examination}

This patient was in phase two (presented with stiff shoulder and was hardly able to move his left shoulder) at his initial visit to our OPD and was diagnosed with primary adhesive capsulitis because there is no previous history of any symptom related to shoulder joint, trauma, or surgery. Movements of cervical spine, right lateral flexion, right rotation and flexion induced a pulling sensation in the antagonist muscle groups (trapezius, levator scapulae and scalene muscles). Aberrant motions with tenderness were detected in the left C2-3, C7-T1, and T3-4 facet joints on static and motion palpation. His left glenohumeral joint active ranges of motion (ROM) were: internal rotation 15 degrees, external rotation 10 degrees, flexion 20 degrees, extension 20 degrees, and abduction 10 degrees. The resisted left glenohumeral joint flexion, abduction, internal and external rotations were graded $2 / 5$. The left glenohumeral joint passive ROM was 5 degrees more in each direction. Posterior and posteroinferior joint movements at the left glenohumeral joint were restricted and painful. There was severe point tenderness over the left deltoid tubercle. The cervical spine and the left shoulder radiographs were unremarkable.

\section{Results and Discussion}

In the present case study, the treating physician applied Hijamah bila shurt (dry cupping) on the following Hijamah points. $1,55,20$, and 115 along with tender points. ${ }^{10}$ Followup was done every $3^{\text {rd }}$ day with assessment done at every
2 weeks interval. Although no trigger point was found in our patient, tender points were treated. A very promising improvement was noted in the range of motion of the shoulder and pain on VAS scale (Tables $1 \& 2$ ). At the affected shoulder, joint range of movements in degrees was measured using a goniometer for abduction, flexion, and extension. Measurement was done for the active and passive motion of each of these movements at baseline and every 2 weeks interval (Table 1). There was a marked improvement in the quality of life and improvement in VAS score for pain, tenderness, and stiffness (Table 2). A previous study by Imam et al. on frozen shoulder with cupping showed improvement in the VAS score with $100 \%$ efficacy at 4 weeks of therapy. ${ }^{11}$ Another study by Raheem et al. on the effectiveness of Hijamah on patients with cervical pain demonstrated that application of dry cupping increased the mean values of cervical ROM in flexion, extension, and right lateral rotation from baseline. Also, a statistically significant reduction in mean VAS scores day 0 vs day 21 ( $p<0.001)$ was observed after cupping. ${ }^{12}$

\section{ROM: Range of Motion}

At baseline, pain, tenderness, and stiffness were noted using Visual Analog Scale (VAS) for pain. After some necessary briefing to the patient, he was told to rate his pain, tenderness, and stiffness at shoulder joint on a linear scale of 1 to 10 after every 2 weeks interval for 8 weeks. At baseline, VAS scores for pain, tenderness, and stiffness were 8,6 and 8 respectively. After 8 weeks of therapy, VAS scores for pain, tenderness, and stiffness were reduced to 1,0 , and 0 respectively with $87.5 \%$ improvement in pain, and complete (100\%) improvement in tenderness and stiffness (Table 2).

Table I.Amelioration of the Patient's Left Shoulder Active and Passive Range of Motion (ROM in Degrees) with Hijamah Therapy

\begin{tabular}{|c|c|c|c|c|}
\hline \multicolumn{2}{|c|}{ ROM in Degrees } \\
\hline \multirow{2}{*}{ ROM } & Abduction & Flexion & Extension \\
\hline \multirow{3}{*}{2 weeks baseline } & Active & 10 & 20 & 20 \\
\cline { 2 - 5 } & Passive & 15 & 25 & 25 \\
\hline \multirow{2}{*}{4 weeks } & Active & 15 & 30 & 30 \\
\cline { 2 - 5 } & Passive & 20 & 35 & 45 \\
\hline \multirow{3}{*}{6 weeks } & Active & 30 & 50 & 45 \\
\cline { 2 - 5 } & Passive & 40 & 60 & 60 \\
\cline { 2 - 5 } & Active & 60 & 75 & 60 \\
\hline \multirow{2}{*}{8 weeks } & Passive & 80 & 90 & 90 \\
\cline { 2 - 5 } & Active & full & full & full \\
\hline
\end{tabular}


Table I.Amelioration of the Patient's Left Shoulder Active and Passive Range of Motion (ROM in Degrees) with Hijamah Therapy

\begin{tabular}{|c|c|c|c|c|c|c|}
\hline \multirow{2}{*}{ Parameters } & \multicolumn{5}{|c|}{ VAS Score (0-10) } & \multirow{2}{*}{$\begin{array}{l}\text { \% Improvement in VAS Score from Baseline to } \\
\text { end of } 8 \text { weeks }\end{array}$} \\
\hline & At baseline & 2 weeks & 4 weeks & 6 weeks & 8 weeks & \\
\hline Pain & 8 & 7 & 5 & 3 & 1 & 87.5 \\
\hline Tenderness & 6 & 6 & 4 & 2 & 0 & 100 \\
\hline Stiffness & 8 & 7 & 6 & 2 & 0 & 100 \\
\hline
\end{tabular}

\section{Conclusion}

In this case study, we have tried to illustrate the potentials of "Hijamah therapy" in a diabetic patient with a frozen shoulder. The frozen shoulder was treated successfully through Hijamah therapy, one of the unique modes of treatment described in the Unani system of medicine. However, further researches with randomised controlled studies on a large scale are required to elaborate the effectiveness of this modality of treatment.

\section{Conflict of Interest: None}

\section{References}

1. Grubbs N. Frozen shoulder syndrome: A review of literature. J Orthop Sports Phys Ther. 1993;18(3):47987. [PubMed] [Google Scholar]

2. Duplay ES. De la periarthritescapulohumeraleet des raideurs de l'epaule qui en son la consequence. Arch Gen Med. 1872.

3. Anton HA. Frozen shoulder. Can Fam Physician. 1993;39:1773-8. [PubMed] [Google Scholar]

4. Wadsworth CT. Frozen shoulder. Phys Ther. 1986;66(12):1878-83. [PubMed] [Google Scholar]

5. Codman EA. The shoulder: Rupture of the Supraspinatus Tendon and Other Lesions in or about the Subacromial Bursa. Boston: Thomas \& Todd Co; 1934.

6. Leahy PM. Active release techniques, soft tissue management system for the upper extremity. Colorado Springs: Active Release Techniques; 1996. p. $40,52,54,58,68$.

7. Lundberg BJ. The frozen shoulder. Clinical and radiographical observations. The effect of manipulation under general anesthesia. Structure and glycosaminoglycan content of the joint capsule. Local bone metabolism. Acta Orthop Scand Suppl. 1969;119:1-59. [PubMed] [Google Scholar]

8. Reeves B. The natural history of the frozen shoulder syndrome.Scand J Rheumatol 1975; 4:193-196.17 Bergman TF, Peterson DH, Lawrence DJ.Chiropractic Technique. New York: Churchill Livingstone Inc. 1993; $555,564,565,568$.

9. Pearsall AW, Speer KP. Frozen shoulder syndrome: diagnostic and treatment strategies in the primary care setting. Med Sci Sports Exerc. 1998;30(4):S33-9.
[PubMed] [Google Scholar]

10. Mulla G, Ghawte SA, Rahman R. Highlights of Hijamah (Cupping Therapy) The Highway to Health. 2nd ed. 2016 ISBN: 9781630413057, 1630413054

11. Imam MH, Alam MI, Perveen A, Goswami A, Khan $Q$, Ahmad T. Management of frozen shoulder with oil cupping massage: A case study. Imam J Appl Sci. 2017;2:49-53. [Google Scholar]

12. Raheem A, Nazli T, Saeed A, Alvi R, Kalaivani M. Effectiveness of Fire Cupping (Hijamah Nariya) versus dry warm Fomentation (Takmeed Yabis) in Chronic Neck Pain - A Randomized Control Trial. J Integ Comm Health. 2019;8(1):21-32. [Google Scholar] 